\title{
THE CONS OF COVID-19 RESTRICTIONS ON PHYSICAL ACTIVITY IN THE ELDERLY; RESULTS OF AN ONLINE SURVEY
}

Turkish Journal of Geriatrics

DOI: 10.31086/tjgeri.2021.197

2021; 24(1): $32-40$

- Ertuğrul DEMIRDEL ${ }^{1}$

- Senem DEMIRDEL ${ }^{2}$

- Sevilay KARAHAN ${ }^{3}$

- Semra TOPUZ ${ }^{4}$

CORRESPONDANCE

\section{${ }^{1}$ Ertuğrul DEMIRDEL}

Ankara Yildirim Beyazit University, Faculty of Health Sciences, Department of Physiotherapy and Rehabilitation, Ankara, Turkey

\section{Phone: +905378223551 \\ e-mail: ertudemirde@gmail.com}

Received: Jan 29, 2021

Accepted: Feb 26, 2021

${ }^{1}$ Ankara Yildirm Beyazit University,

Faculty of Health Sciences, Department of Physiotherapy and Rehabilitation, ANKARA, Turkey

2 University of Health Sciences Turkey, Gulhane Faculty of Health Sciences, Department of Physiotherapy and Rehabilitation, ANKARA, Turkey

${ }^{3}$ Hacettepe University, Faculty of Medicine, Department of Biostatistics, ANKARA, Turkey

${ }^{4}$ Hacettepe University, Faculty of Physical Therapy and Rehabilitation, ANKARA, Turkey

\section{Abstract}

Introduction: The aim of this study was to evaluate the physical activity level of the elderly, physical activity barriers during the COVID-19 restrictions and the effects of the restrictions on well-being.

Materials and method: An online survey was used that included demographic characteristics, the Physical Activity Scale for the Elderly, Physical Activity Barriers Scale for the Elderly and questions about well-being. Stepwise logistic regression analysis was performed to examine the risk factors for physical inactivity.

Results: Of 131 respondents (mean age, $70.97 \pm 5.87$ years), $82.4 \%$ stated that they were less physically active due to the restrictions. Mean physical activity score was $80.79 \pm 65.18$ and the most common physical activity was household activities. Inactive elderly had more physical activity barriers $(p=0.003)$. Risk factors for physical inactivity were age, medication, other occupants of the house and house type (Odds ratios were 1.13, 3.3, 3.25, 2.52 and 95\% confidence intervals were 1.03-1.23, 1.36-8.05, 1.33-7.93, 1.05-6.06 respectively, $\mathrm{p}<0.05)$. Participants stated that they had gained weight, they felt more bored, anxious, angry, uneasy $(47.3 \%, 78.6 \%, 75.6 \%, 54.2 \%, 74 \%$ of the participants respectively) since the curfews started.

Conclusion: During the restrictions, the level of physical activity of the elderly decreased. Risk factors for physical inactivity are older age, taking multiple medications, living with a caregiver and living in a home without a garden or terrace. Measures to increase the level of physical activity and decrease physical activity barriers should be taken into consideration for well-being during the restrictions.

Keywords: Aged; Exercise; Pandemics 


\section{INTRODUCTION}

The World Health Organization (WHO) declared COVID-19 a pandemic in March 2020. As the elderly are at higher risk of a poor prognosis and mortality due to COVID-19 than younger and middle-aged people, many countries have taken special precautions for the elderly, including enforcing social isolation, staying at home and not meeting others (1).

Social isolation increases the risk of cardiovascular, autoimmune, neuro-cognitive and mental health problems in the elderly $(1,2)$. In addition to psychological problems related to stress in the isolation process, health is negatively affected due to the limited possibilities for physical activity (PA) (3).

Acute physical inactivity quickly disrupts metabolic and inflammatory homeostasis in adults and especially the elderly (4). It has been reported that exercise of moderate to vigorous intensity can increase immunity to viral infections, reduce the harmful effects of stress on immunity (5).

The WHO recommends at least 150 min of moderate intensity or 75 min of vigorous intensity PA per week (6). Poor health behaviours, such as not meeting this recommendation, might be central to the association between social isolation and psychological and physical health problems (7). Determining the factors associated with the application of the recommended PA level and PA barriers of the elderly during the COVID-19 restrictions could guide the development of measures to be taken during possible restriction periods later in the pandemic to apply PA approaches. Although a few studies have examined the effects of the restrictions on the PA level of adults $(8,9)$, there is a limited number of studies examining the elderly's PA levels and PA barriers, and the effects of the restrictions on their perceptions of well-being. The aim of this study was to investigate the PA levels and PA barriers of the elderly during the quarantine period, the factors affecting PA and perceptions about some parameters of well-being (e.g. anxiety, boredom, pain).

\section{MATERIALS AND METHOD}

Curfews for individuals aged $\geq 65$ years started on 21 March 2020 in Turkey. On June 9, they were allowed to go out between 10.00 and 20.00 every day. This study was conducted between 3 and 9 June 2020 . Approval for this study was granted by the Ankara Yıldırım Beyazıt University Ethics Board.

Volunteers aged $\geq 65$ years were included in the study. The participants were recruited through snowball sampling using social media connections of the authors. An online survey was prepared to evaluate the PA levels, PA barriers and perceptions about some parameters of well-being of the elderly during the COVID-19 restrictions. The survey included an introduction section describing the aims of the survey and ethics information for the participants. It was sent to 10 elderly people who use smartphones in order to determine the difficulties that may be experienced in the comprehensibility, answering and submitting of the questions in the online survey. The difficulties they faced were learned by talking to these people by phone. After these difficulties were resolved, the work continued with the online survey, which was made very simple to answer and submit. The online link of the survey was sent to the participants via message or e-mail. Elderly individuals using social media filled out the questionnaire themselves. A survey link was sent to the relatives of the other elderly people and the elderly filled the survey with the help of their relatives. All participants marked an option stating that they voluntarily participated in the study before starting the survey.

In this survey, the sociodemographic characteristics of the participants were attained. In addition to the Physical Activity Scale for the Elderly and Physical Activity Barriers Scale for the Elderly questionnaires, questions were prepared by the authors to determine the effects of the COVID-19 period on PA and health perceptions. These questions were answered with "yes" or "no". There were also questions related to the physical activities that individuals did and could not do during the restrictions. A total of 65 questions were asked to the participants and the participants stated that 15-20 minutes was required to complete the online survey. 


\section{Outcome Measures}

\section{Physical Activity Scale for the Elderly}

The Physical Activity Scale for the Elderly (PASE) is a self-reported questionnaire developed by Washburn et al. to evaluate the level of PA of elderly individuals (10). The PASE includes leisure time activities, household activities and work-related activities over a one-week period and may be applied by telephone, mail or in person. The leisure time activities section is scored based on weekly activity duration and empirically derived item weighting. The household activities section is scored based on participation (yes/no) and item weighting. The work-related activities section is scored based on participation (yes/no), weekly activity duration and item weighting. The total score is obtained from the sum of these section scores. The Turkish version of the questionnaire has been shown to be valid and reliable (11).

A binary PA variable (inactive or moderate/intense activity) was created to determine the factors affecting moderate/intense activity. Those with a PASE total score $>90$ were considered to be doing moderate and intense PA (12).

\section{Physical Activity Barriers Scale for the Elderly}

The Physical Activity Barriers Scale for the Elderly (PABS-E) is a valid and reliable scale developed by Demirdel et al. to evaluate PA barriers in the elderly. PABS-E contains 30 items about personal and environmental factors and factors related to daily routines. Each item is scored on a 3-point Likert-type scale ( $1=$ disagree, $2=$ undecided and $3=$ agree). The total score ranges from 30-90, with higher scores indicating more PA barriers (6).

\section{Data Analysis}

Data were analysed using SPSS for Windows version 20.0 software (IBM SPSS Inc., Armonk, NY, USA). Categorical variables were expressed as number and percentage, and continuous variables as mean and standard deviation values. The Mann Whitney-U test was used to compare the PABS-E scores of individuals with a PASE score below and above 90. Stepwise logistic regression analysis was performed to examine the factors affecting the risk of physical inactivity during the COVID-19 restrictions. Variables with $p<0.2$ in univariate analyses were included in the regression analysis. A 5\% type-1 error level was used to infer statistical significance. A post-hoc power analysis was performed to show the adequacy of sample size. GPower 3.1.9.4 (Heinrich-Heine-Universität Düsseldorf) programme was used for determine the effect size and power analysis. Effect size and power was calculated for comparing PASE groups in terms of PABS-E scores. Power was also calculated for logistic regression analysis.

\section{RESULTS}

Evaluation was made of 131 elderly individuals with a mean age of $70.97 \pm 5.87$ years (range, 65-90 years). The descriptive characteristics of the participants are shown in Table 1.

The PASE and PABS-E scores of the participants are shown in Table 2. The items with the highest score in the personal factors sub-section of PABS-E were "I do not do physical activity because I get tired very quickly" and "I do not do it because I feel pain during physical activity" with $1.76 \pm 0.94$ points and $1.67 \pm 0.9$ points, respectively. The items with the highest score in the environmental factors sub-section were "I do not do physical activity because I am not in the habit of doing so" and "I do not do physical activity because group activities are not organised for the elderly" with $1.85 \pm 0.96$ points and $1.67 \pm 0.91$ points, respectively. The item with the highest score in the factors related to daily routines sub-section was "I do not do physical activity because I think I am active enough in my daily life" with $1.77 \pm 0.89$ points.

When the PA barriers of individuals with a PASE score of less than 90 and more than 90 were compared, a significant difference was found between personal factors, environmental factors and PABS-E total scores $(p<0.05)$. In addition, the power and effect size of the study were found to be good (Table 3).

Risk factors for physical inactivity during the restrictions were determined as older age, taking multiple medications, living with caregivers and liv- 
Table 1. Descriptive characteristics of elderly individuals $(\mathrm{N}=131)$

\begin{tabular}{|c|c|c|}
\hline Features & $\mathbf{N}$ & $\%$ \\
\hline \multicolumn{3}{|l|}{ Gender } \\
\hline Male/ Female & $77 / 54$ & $58.8 / 41.2$ \\
\hline \multicolumn{3}{|l|}{ Chronic health conditions } \\
\hline Diabetes mellitus/Hypertension/Heart disease/Pulmonary disease/Other & $40 / 59 / 36 / 18 / 63$ & $30.5 / 45 / 27.4 / 13.7 / 58$ \\
\hline \multicolumn{3}{|l|}{ Medication } \\
\hline Up to one medication/ Multiple medications & $47 / 84$ & $35.9 / 64.1$ \\
\hline \multicolumn{3}{|l|}{ Walking aid } \\
\hline Yes/No & 22/109 & $16.8 / 83.2$ \\
\hline \multicolumn{3}{|l|}{ People who lived together } \\
\hline $\begin{array}{l}\text { Alone at home or just with a spous/ At home with their children, spouse and } \\
\text { children, or in a nursing home }\end{array}$ & $77 / 54$ & $58.8 / 41.2$ \\
\hline \multicolumn{3}{|l|}{ House type } \\
\hline House without garden or terrace/ House with garden or terrace & $50 / 81$ & $38.2 / 61.9$ \\
\hline \multicolumn{3}{|l|}{ Setting } \\
\hline Urban/ Rural & $89 / 42$ & $67.9 / 32.1$ \\
\hline \multicolumn{3}{|l|}{ Education } \\
\hline $1-8$ years $/ 9+$ years & $65 / 66$ & $49.6 / 50.4$ \\
\hline \multicolumn{3}{|l|}{ Falls in 1 year } \\
\hline Yes/No & $32 / 99$ & $24.4 / 75.6$ \\
\hline
\end{tabular}

Table 2. Physical Activity Scale for Elderly and Physical Activity Barriers Scale for Elderly scores $(\mathrm{N}=131)$

\begin{tabular}{|l|c|}
\hline & $\mathbf{M} \pm$ SD (Min-Max) \\
\hline PASE Leisure time activities & $26.61 \pm 37.21(0-274.56)$ \\
\hline PASE Household activities & $48.53 \pm 42.01(0-171)$ \\
\hline PASE Work-related activities & $5.64 \pm 25.16(1-180)$ \\
\hline PASE Total & $80.79 \pm 65.18(0-355.56)$ \\
\hline PABS-E Personal factors & $18.61 \pm 7.6(0-36)$ \\
\hline PABS-E Environmental factors & $18.87 \pm 6.1(0-36)$ \\
\hline PABS-E Factors related daily routines & $7.35 \pm 2.56(0-15)$ \\
\hline PABS-E Total & $44.83 \pm 13.88(30-81)$ \\
\hline
\end{tabular}

Data is presented as Mean \pm Standard deviation (minimum-maximum). $\mathrm{PASE}=$ Physical Activity Scale for Elderly; PABS-E= Physical Activity Barriers Scale for the Elderly. ing in a home without a garden or terrace (Table 4). Power of detecting an odds ratio as 3.258 for living with caregivers was 0.795 .

The effects of the restrictions on perceptions of some parameters of well-being can be seen in Table 5.

In response to the question "What physical activity or activities did you do regularly during the COVID-19 restrictions?", 26 people (19.8\%) stated that they did not do any PA, and 62 (47.3\%) stated that they used to walk. Some of those who reported previous walking stated that they walked inside the house, on the balcony, in the garden or on a walking band, while some stated that they walked outside on the permitted days. A total of 23 people (17.5\%) 
Table 3. Physical Activity Barriers Scale for Elderly (PABS-E) scores of active and inactive elderly

\begin{tabular}{|l|c|c|c|c|c|}
\hline \multicolumn{1}{|c|}{ PABS-E Scores } & $\begin{array}{c}\text { PASE score <90 } \\
(\mathbf{n}=\mathbf{8 5})\end{array}$ & $\begin{array}{c}\text { PASE score }>\mathbf{9 0} \\
(\mathbf{n}=\mathbf{4 6})\end{array}$ & $\mathbf{p}^{*}$ & Effect size & Power \\
\hline Personal factors & $20.01 \pm 7.95$ & $16.04 \pm 6.18$ & $\mathbf{0 . 0 0 3}$ & $\mathbf{0 . 5 5 6}$ & $\mathbf{0 . 8 4 0}$ \\
\hline Environmental factors & $19.92 \pm 6.35$ & $16.91 \pm 5.12$ & $\mathbf{0 . 0 0 5}$ & $\mathbf{0 . 5 2 2}$ & $\mathbf{0 . 7 8 9}$ \\
\hline Factors related Daily routines & $7.27 \pm 2.23$ & $7.50 \pm 3.11$ & 0.693 & 0.085 & 0.074 \\
\hline Total & $47.21 \pm 13.87$ & $40.45 \pm 12.94$ & $\mathbf{0 . 0 0 3}$ & $\mathbf{0 . 5 0 4}$ & $\mathbf{0 . 7 6 1}$ \\
\hline
\end{tabular}

Data is presented as Mean \pm Standard deviation. *: Mann Whitney U test, PASE= Physical Activity Scale for Elderly; PABS-E= Physical Activity Barriers Scale for the Elderly.

stated that they did housework, 18 (13.7\%) did garden work, 24 (18.3\%) continued with pre-planned exercise programmes, $2(1.5 \%)$ were involved in taking care of their grandchildren, 12 (9.1\%) worked in a job and 10 (7.6\%) performed prayers.

In answer to the question "What physical activity or activities did you do before but could not do due to COVID-19 restrictions?", 65 people (49.6\%) stated that they could not walk outside. Of these people, some stated that they could not take long walks outside, walk in specific areas, or go shopping, to the mosque or to meet their friends. A total of 13 (9.9\%) stated that they could not participate in the sports that they used to do regularly, including running, swimming, tennis and cycling.

\section{DISCUSSION}

The results of this study showed that the level of PA of the elderly during the COVID-19 restrictions was low, the COVID-19 restrictions were a barrier to PA and other frequently mentioned barriers were a lack of PA habits, rapidly becoming fatigued, pain, a lack of group activities and the idea of being sufficiently active in daily life. Older age, taking multiple medications, living with a caregiver and living in a home without a garden or terrace are the risk factors of physical inactivity during the restrictions. $78.6 \%$ of the participants reported feeling more bored, $75.6 \%$ of the participants reported feeling anxious, $54.2 \%$ of the participants reported feeling angry and $74 \%$ of the participants reported feeling uneasy since the COVID-19 restrictions started.

The total PASE score was found to be lower than in other studies that have evaluated PA level us- ing PASE $(10,11)$. Of the participants in the current study, $82.4 \%$ reported that they were more active before the restrictions started. This confirms that COVID-19 restrictions reduced PA in individuals aged $\geq 65$ years. A large-scale study in Asia, Afri$\mathrm{ca}$ and European countries has also proven that COVID-19 restrictions reduced the level of PA and increased sitting time (9).

Aktürk et al. stated that the most common physical activities in Turkish society were walking, light sports and exercises, gardening and light housework (12). In the current study, the highest score in the PASE sub-sections was in the household activities section. The reason for this may be the absence of leisure time activities that can be performed outdoors due to COVID-19 restrictions.

In a previous study of a similar population in Turkey, PABS-E was found to be $49.6 \pm 14.3$ (6). However, in the current study conducted during the COVID-19 restrictions, the PABS-E score was seen to have decreased. As the most important PA barriers during the COVID-19 restrictions were curfews and fear of contamination, it is to be expected that the PABS-E score would be lower because $76.3 \%$ of the participants stated that curfews prevented PA, and $61.8 \%$ stated that they did not do PA because they were afraid of the risk of infection. A negative relationship has been shown between PA barriers and PA level (6). The finding in the current study that active individuals had fewer PA barriers supports this relationship.

It has been stated that the most important PA barriers for people aged $\geq 60$ years are insufficient guidance and a lack of role models (13). These fac- 
Table 4. Logistic regression analysis predictors of physical inactivity in COVID-19 restriction period

\begin{tabular}{|c|c|c|c|c|c|c|}
\hline & \multirow{2}{*}{$\begin{array}{c}\text { PASE } \\
\text { score }<90 \\
(n=85)\end{array}$} & \multirow{2}{*}{$\begin{array}{c}\text { PASE } \\
\text { score }>90 \\
(n=46)\end{array}$} & \multirow{2}{*}{$\begin{array}{c}\text { Univariate } \\
\text { analysis } \\
\text { p }\end{array}$} & \multicolumn{2}{|c|}{ Multivariate analysis } \\
\hline & & & & & Odds ratio $(95 \% \mathrm{Cl})$ & $p$ \\
\hline \multicolumn{2}{|l|}{ Age } & $72.2 \pm 6.6$ & $68.8 \pm 3.2$ & $<0.001 *$ & $1.130(1.031-1.238)$ & 0.009 \\
\hline \multirow[t]{2}{*}{ Gender } & Male & 49 (63.6\%) & 28 (36.4\%) & \multirow{2}{*}{0.864} & & \\
\hline & Female & $36(66.7 \%)$ & $18(33.3 \%)$ & & & \\
\hline \multirow{2}{*}{$\begin{array}{l}\text { Chronic health } \\
\text { conditions }\end{array}$} & Yes & $76(66.7 \%)$ & 38 (33.3\%) & \multirow{2}{*}{0.404} & & \\
\hline & No & $9(52.9 \%)$ & $8(47.1 \%)$ & & & \\
\hline \multirow[t]{2}{*}{ Pulmonary disease } & Yes & 15 (78.9\%) & $4(21.1 \%)$ & \multirow{2}{*}{0.259} & & \\
\hline & No & $70(62.5 \%)$ & $42(37.5 \%)$ & & & \\
\hline \multirow[t]{2}{*}{ Diabetes Mellitus } & Yes (reference category) & $22(55 \%)$ & $18(45 \%)$ & \multirow{2}{*}{$0.170^{\star}$} & & \\
\hline & No & $63(69.2 \%)$ & $28(30.8 \%)$ & & $2.226(0.875-5.664)$ & 0.093 \\
\hline \multirow[t]{2}{*}{ Hypertension } & Yes & $39(66.1 \%)$ & 20 (33.9\%) & \multirow{2}{*}{0.936} & & \\
\hline & No & $46(63.9 \%)$ & $26(36.1 \%)$ & & & \\
\hline \multirow[t]{2}{*}{ Heart disease } & Yes & 28 (77.8\%) & $8(22.2 \%)$ & \multirow{2}{*}{$0.090^{*}$} & & \\
\hline & No & 57 (60\%) & $38(40 \%)$ & & & \\
\hline \multirow{2}{*}{$\begin{array}{l}\text { Other chronic } \\
\text { health conditions }\end{array}$} & Yes & $46(74.2 \%)$ & $16(25.8 \%)$ & \multirow{2}{*}{$0.053^{\star}$} & & \\
\hline & No & $39(56.5 \%)$ & $30(43.5 \%)$ & & & \\
\hline \multirow[t]{2}{*}{ Medication } & Multiple medications & $62(73.8 \%)$ & 22 (26.2\%) & \multirow[b]{2}{*}{$0.008^{\star}$} & $3.309(1.360-8.055)$ & 0.008 \\
\hline & $\begin{array}{l}\text { Up to one medication } \\
\text { (reference category) }\end{array}$ & $23(48.9 \%)$ & $24(51.1 \%)$ & & & \\
\hline \multirow[t]{2}{*}{ Walking aid } & Yes & $18(81.8 \%)$ & $4(18.2 \%)$ & \multirow{2}{*}{$0.114^{\star}$} & & \\
\hline & No & $67(61.5 \%)$ & $42(38.5 \%)$ & & & \\
\hline \multirow[t]{2}{*}{$\begin{array}{l}\text { People who lived } \\
\text { together }\end{array}$} & $\begin{array}{l}\text { At home or nursing home } \\
\text { with the caregiver }\end{array}$ & $43(79.6 \%)$ & $11(20.4 \%)$ & \multirow{2}{*}{$0.006^{*}$} & $3.258(1.338-7.931)$ & 0.009 \\
\hline & $\begin{array}{l}\text { Alone at home or just with a } \\
\text { spouse (reference category) }\end{array}$ & 42 (54.5\%) & 35 (45.5\%) & & & \\
\hline \multirow[t]{2}{*}{ House type } & $\begin{array}{l}\text { The house without garden } \\
\text { or terrace }\end{array}$ & $37(74 \%)$ & $13(26 \%)$ & \multirow{2}{*}{$0.126^{\star}$} & $2.525(1.052-6.064)$ & 0.038 \\
\hline & $\begin{array}{l}\text { The house with garden or } \\
\text { terrace (reference category) }\end{array}$ & 48 (59.3\%) & 33 (40.7\%) & & & \\
\hline \multirow[t]{2}{*}{ Setting } & Urban & $63(70.8 \%)$ & $26(29.2 \%)$ & \multirow{2}{*}{$0.062^{\star}$} & & \\
\hline & Rural & $22(52.4 \%)$ & $20(47.6 \%)$ & & & \\
\hline \multirow[t]{2}{*}{ Education } & $1-8$ years & 45 (69.2\%) & 20 (30.8\%) & & & \\
\hline & $9+$ years & 40 (60.6\%) & 26 (39.4\%) & 0.395 & & \\
\hline Falls in 1 year & Yes & 25 (78.1\%) & 7 (21.9\%) & 0 M & & \\
\hline & No & 60 (60.6\%) & 39 (39.4\%) & $0.111^{\star}$ & & \\
\hline
\end{tabular}

Data is presented as Mean \pm Standard deviation and $n(\%)$. ${ }^{*} p<0.2 ;$ PASE $=$ Physical Activity Scale for Elderly 
Table 5. Physical activity and well-being perceptions of the elderly in the period of COVID-19 restrictions

\begin{tabular}{|l|c|c|}
\hline & $\mathbf{n}$ & $\%$ \\
\hline I was more physically active before the COVID-19 restrictions & 108 & 82.4 \\
\hline Curfews prevent me from doing physical activity & 100 & 76.3 \\
\hline I'm not doing physical activity because I'm afraid of the risk of COVID-19 contamination & 81 & 61.8 \\
\hline COVID-19 restrictions adversely affect my existing diseases & 70 & 53.4 \\
\hline My pain has increased since COVID-19 restrictions started & 42 & 32.1 \\
\hline Stiffness in my joints increased since COVID-19 restrictions started & 65 & 49.6 \\
\hline I have gained weight since the COVID-19 restrictions started & 62 & 47.3 \\
\hline Boredom has increased since COVID-19 restrictions started & 103 & 78.6 \\
\hline I feel more anxious since COVID-19 restrictions started & 99 & 75.6 \\
\hline I feel more angry since COVID-19 restrictions started & 71 & 54.2 \\
\hline I feel more uneasy since COVID-19 restrictions started & 74 & 74 \\
\hline There are physical activity / activities that I did before but could not do due to COVID-19 restrictions & 73 & 55.7 \\
\hline
\end{tabular}

tors are important for gaining an exercise habit. It is common for physical inactivity or active behaviour not to become a routine or habit (14). One of the most commonly reported barriers in this study was habit. Exercise habits are related to demographic, cultural, environmental, socioeconomic and psychological factors $(12,15)$. It is important for the elderly in Turkish society to gain positive health behaviours such as exercise habits in order to be able to continue these habits during pandemics. Other barriers which were frequently stated in this study, such as feeling fatigued quickly, pain, a lack of organised group exercise activities and daily routines, have also been specified in studies conducted before the pandemic $(16,17)$. To overcome these barriers, exercise programmes that can be performed at home (and can therefore be applied during pandemics) can be organised to increase motivation. The programmes can be selected by considering the self-efficacy of individuals without exercise habits, and the type, frequency, intensity and duration of the exercises can be regulated to prevent fatigue and pain (18). Creating web-based classes for group exercises can be useful for increasing PA during pandemics.
Aktürk et al. reported depression, age, the presence of a caregiver and chronic illness as determinants of PASE score (12). Similarly, in the current study, factors that increase the risk of lower PA were found to be older age, taking multiple medications, living with a caregiver or living in a house without a garden or terrace. This also shows that the predictors of PA in Turkey under normal conditions and during the COVID-19 restrictions are similar. Only house type became more important during the restrictions because outdoor PA decreased.

Taking multiple medications can be linked to suffering from chronic diseases. The relationship between chronic diseases and PA has been shown in previous studies $(10,19)$. For those living as part of multigenerational families, younger family members undertake household chores. This can affect the PA levels of the elderly as they need to do very little work. Aktürk et al. also found that having home-help affects the level of PA (12).

It has been shown that the level of PA of adults decreased during the COVID-19 restrictions, and this decrease was associated with symptoms of depression, anxiety and stress (20). Walking and PA 
have been associated with lower depression, anxiety and psychological stress, and higher subjective well-being. Green, outdoor and natural environments have been reported to be beneficial for mental health outcomes (21). In this context, one of the reasons why most of the participants in the current study reported feeling more bored, anxious, angry and uneasy may have been the restrictions on walking outdoors, which decreased PA. Decreased PA may not be the only reason for the impact on physical and mental health, but increased PA is known to improve symptoms of depression and anxiety (22, 23). In addition, regular exercise has been shown to be associated with less musculoskeletal pain and joint stiffness (24). Therefore, promoting regular PA during a pandemic could contribute to the reduction of problems such as pain, stiffness, boredom and anxiety, which the current study participants stated had increased during the restrictions. Although a wide range of physical activities can be done outdoors, the elderly should be encouraged to do PA at home to maintain physiological functions and reserves of the organ systems, reduce the negative mental and physical consequences of the COVID-19 restrictions and have a positive effect on the immune system (18).

This study was conducted in a period in which curfews for the elderly were strictly enforced. In this respect, it is important in terms of reflecting the social isolation and physical activity behaviors of the elderly in our country and being a guide for determining the physical activity interventions for the elderly in such periods. As the pandemic continues, the measures taken for the elderly will continue, so

\section{REFERENCES}

1. Aki ÖE. COVID-19 Pandemic and the mental health of elderly. Turkish Journal of Geriatrics 2020;23(3). (DOI: 10.31086/tjgeri.2020.165)

2. Gerst-Emerson K, Jayawardhana J. Loneliness as a public health issue: the impact of loneliness on health care utilization among older adults. American Journal of Public Health 2015;105(5):1013-9. (PMID: 25790413)

3. Plagg B, Engl A, Piccoliori G, Eisendle K. Prolonged social isolation of the elderly during COVID-19: Be- vaccination is also important in increasing the physical activity level of the elderly. In this process, there are many publications suggesting the importance of physical activity for the elderly $(3,14,18)$. However, research studies are limited due to the inability to come face to face. This study is the first study conducted online in our country with valid and reliable physical activity scales specific to the elderly during the restriction period. Furthermore, this is the first study examining factors affecting PA, PA barriers and parameters of well-being during the quarantine in Turkey. However, in this study, it was only possible to reach a limited number of elderly people because internet use is not universal among the elderly and the restrictions were relaxed shortly after the study started. However, the post-hoc power was found to be good. Although most of the participants (82.4\%) reported that they were more active before the COVID-19 restrictions, the fact that the previous PA level could not be evaluated can be considered as a limitation of this study.

\section{CONCLUSION}

It should be taken into consideration that curfews, which are important in this context, affect the level of PA in the elderly. Attention should also be paid to mental and physical health problems that may result from decreased PA. Therefore, knowing the PA barriers and the factors affecting moderate to high intensity PA can be of guidance in terms of the approaches that can be applied to increase PA both under normal circumstances and in the event of future pandemics.

tween benefit and damage. Archives of Gerontology and Geriatrics 2020;89:104086. (PMID: 32388336)

4. Martinez-Ferran M, de la Guía-Galipienso F, Sanchis-Gomar F, Pareja-Galeano H. Metabolic Impacts of Confinement during the COVID-19 Pandemic Due to Modified Diet and Physical Activity Habits. Nutrients 2020;12(6):1549. (PMID: 32466598)

5. Duggal NA, Niemiro G, Harridge SD, Simpson RJ, Lord JM. Can physical activity ameliorate immunosenescence and thereby reduce age-related multi-mor- 
bidity? Nature Reviews Immunology 2019;19(9):56372. (PMID: 31175337)

6. Demirdel S, Sahinoglu D, Karahan S, Demirdel E, Topuz S. Development of the physical activity barriers scale for elderly individuals. Turkish Journal of Geriatrics 2018;21(4). (DOI: 10.31086/tjgeri.2018.68)

7. Richard $A$, Rohrmann $S$, Vandeleur $C L$ et al. Loneliness is adversely associated with physical and mental health and lifestyle factors: Results from a Swiss national survey. PloS One 2017;12(7):e0181442. (PMID: 28715478)

8. Lesser IA, Nienhuis CP. The Impact of COVID-19 on Physical Activity Behavior and Well-Being of Canadians. International Journal of Environmental Research and Public Health 2020;17(11):3899. (PMID: 32486380)

9. Ammar $A$, Brach $M$, Trabelsi $K$ et al. Effects of COVID-19 Home Confinement on Eating Behaviour and Physical Activity: Results of the ECLB-COVID19 International Online Survey. Nutrients 2020;12(6):1583. (PMID: 32481594)

10. Washburn RA, Smith KW, Jette AM, Janney CA. The Physical Activity Scale for the Elderly (PASE): development and evaluation. Journal of Clinical Epidemiology 1993;46(2):153-62. (PMID: 8437031)

11. Ayvat $E$, Kilinc M, Kirdi N. The Turkish version of the Physical Activity Scale for the Elderly (PASE): its cultural adaptation, validation, and reliability. Turkish Journal of Medical Sciences 2017;47(3):908-15. (PMID: 28618742)

12. Aktürk Ü, Aktürk $S$, Erci B. The effects of depression, personal characteristics, and some habits on physical activity in the elderly. Perspectives in Psychiatric Care 2019;55(1):112-8. (PMID: 30171700)

13. Allender S, Cowburn G, Foster C. Understanding participation in sport and physical activity among children and adults: a review of qualitative studies. Health Education Research 2006;21(6):826-35. (PMID: 16857780)

14. de Oliveira Neto L, Elsangedy HM, de Oliveira Tavares VD, Teixeira CVLS, Behm DG, Da Silva-Grigoletto ME. \# TrainingInHome-Home-based training during COVID-19 (SARS-COV2) pandemic: physical exercise and behavior-based approach. Revista Brasileira de Fisiologia do Exercício 2020;19(2):9-19. (DOI: 10.33233/rbfe.v19i2.4006)

15. McPhee JS, French DP, Jackson D, Nazroo J, Pendle- ton N, Degens H. Physical activity in older age: perspectives for healthy ageing and frailty. Biogerontology 2016;17(3):567-80. (PMID: 26936444)

16. Baert V, Gorus E, Mets T, Geerts C, Bautmans I. Motivators and barriers for physical activity in the oldest old: a systematic review. Ageing Research Reviews 2011;10(4):464-74. (PMID: 21570493)

17. Yarmohammadi S, Saadati HM, Ghaffari M, Ramezankhani A. A systematic review of barriers and motivators to physical activity in elderly adults in Iran and worldwide. Epidemiology and Health 2019;41. (PMID: 31801319)

18. Jiménez-Pavón D, Carbonell-Baeza A, Lavie CJ. Physical exercise as therapy to fight against the mental and physical consequences of COVID-19 quarantine: Special focus in older people. Progress in Cardiovascular Diseases 2020. (PMID: 32220590)

19. Giuli C, Papa R, Mocchegiani E, Marcellini F. Predictors of participation in physical activity for community-dwelling elderly Italians. Archives of Gerontology and Geriatrics 2012;54(1):50-4. (PMID: 21453978)

20. Stanton R, To QG, Khalesi S, et al. Depression, Anxiety and Stress during COVID-19: Associations with Changes in Physical Activity, Sleep, Tobacco and Alcohol Use in Australian Adults. International Journal of Environmental Research and Public Health 2020;17(11):4065. (PMID: 32517294)

21. Kelly P, Williamson C, Niven AG, Hunter R, Mutrie N, Richards J. Walking on sunshine: scoping review of the evidence for walking and mental health. British Journal of Sports Medicine 2018;52(12):800-6. (PMID: 29858467)

22. Mochcovitch MD, Deslandes AC, Freire RC, Garcia RF, Nardi AE. The effects of regular physical activity on anxiety symptoms in healthy older adults: a systematic review. Brazilian Journal of Psychiatry 2016;38(3):25561. (PMID: 27579597)

23. Dinas $P$, Koutedakis $Y$, Flouris A. Effects of exercise and physical activity on depression. Irish Journal of Medical Science 2011;180(2):319-25. (PMID: 21076975)

24. Heesch KC, Miller YD, Brown WJ. Relationship between physical activity and stiff or painful joints in midaged women and older women: a 3-year prospective study. Arthritis Research \& Therapy 2007;9(2):R34. (PMID: 17394630) 